NOTE ON CERTAIN PROTOZOAN ORGANISMS OBSERVED IN THE RECTAL AND CACAL CONTENTS OF THE TURKEY AND FOWL.

By the Same.

THE object of the present note is to give a brief account of certain (I) flagellated and (2) spirally-formed organisms encountered in the course of examination of the fluid and semi-fluid rectal and cæcal contents of the turkeys which formed the subjects of study of the

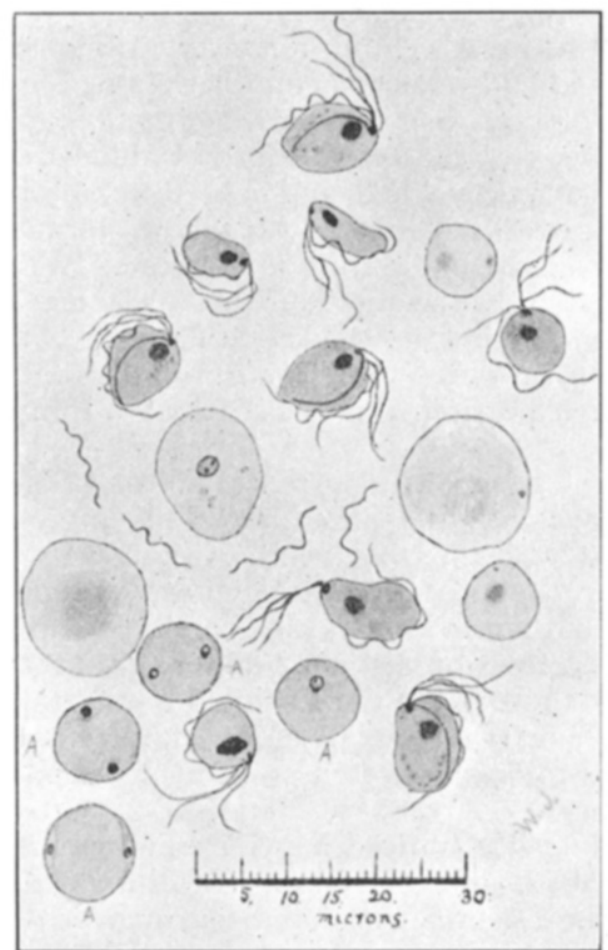

Drawing to scale of cxcal contents of diseased turkey, illustrating some of the flagellate and other organisms there present. Those organisms marked $A$ in the illustration were from preparations fixed wet in corrosive acetic alcohol and stained with hematoxylin, the remainder being from preparations fixed wet in osmic vapour and stained by the Roman. owsky method.

blackhead disease. Similar bodies have been met with in fowls which were apparently in a healthy condition, as well as in others the subjects of diarrhoea. Examples of these organisms are shown in the accompanying illustration, which is a drawing to scale of preparations from the rectal and cacal content of a turkey viewed through the microscope.

\title{
I.-Flagellated Organisins.
}

As reference to the illustration will show, this is a bi-nucleated, fragellated organism possessing an undulating membrane,-it is, 
in fact, a typical trichomonad. In fresh preparations the movements of this organism are very active, for not only is lashing with the long flagella very evident, but, in addition, the body protoplasm of the organism constantly undergoes more or less well-marked alteration in form, it being endowed with the power of amoboid movement.

The flagellate possesses a round, oval, or pear-shaped body. The cytoplasm is homogeneous, or in some specimens finely granular. Situated in the anterior part of the organism (the flagellar extremity) is a somewhat prominent and large nucleus, whilst close up to the same end of the body is a second smaller mass of chromatin-the blepharoplast or kineto-nucleus. Arising from the latter are three to four long, delicate, free, and forwardly directed flagella. Also arising from the kineto-nucleus is another single long flagellum, this, however, being directed in a backward direction. This last is connected with the body of the organism throughout the greater portion of its extent by a well-marked and folded undulating membrane,in fact, this backwardly directed flagellum forms the thickened (flagellar) border of the undulating membrane. When it reaches the posterior (a-flagellar) extremity of the organism the undulating membrane terminates, but its thickened flagellar border is prolonged some distance beyond the posterior extremity of the body of the flagellate as a free portion, this constituting a thin delicate trailing flagellum.

Reference to the figure will show still another organella present in some of the flagellates-the axostyle. This organella arises from the blepharoplast and runs backwards in the body of the organism, terminating near the posterior (a-flagellar) end of the latter. In some specimens, but not in all, it is also possible to distinguish one, and in other cases two rows of distinct granules situated along the body of the flagellate, these being the so-called basal granules. In one or two instances where two rows of such granules could be made out these were found to converge to a point near the posterior extremity of the organism.

Occasionally one has noticed flagellates, apparently identical with those just described, in the contents of the cæca and rectum of chickens when the examination has been made shortly after death. Moreover, in these birds there have also been seen at times smaller spherical, oval, or pear-shaped organisms with only two flagella (occasionally, indeed, but one could be made out), and devoid of an undulating membrane, axostyle, etc. These last organisms bear a close morphological resemblance to certain flagellates observed by the writer on two occasions in necrotic nodular areas in the livers of young pigeons (vide The Journal of Comparative Pathology and Therapeutics, I907).

In both the turkey and fowl one has also noticed at times the presence of mono-cercomonad forms of flagellates, very similar to the above-described trichomonads in point of size and shape, and possessing, like them, three to four anteriorly directed flagella. These mono-cercomonad forms differ, however, from the trichomonads in that an undulating membrane and backwardly directed flagellum are absent in their case. It seems likely that these two forms may represent merely different stages in the life-cycle of the one flagellate. 
The trichomonad here described corresponds fairly closely with the trichomonas eberthi (Kent), and also for the most part with a similar flagellate encountered by Fantham in the cæcal and rectal contents of grouse.

As already remarked, the flagellate has been found present in the fluid and semi-fluid cæcal and rectal contents of turkeys and chickens which were to all appearance in a healthy condition. It has also been encountered-sometimes indeed in very great numbers--in the rectal and cæcal contents of turkeys the subjects of blackhead.

As pointed out elsewhere, we regard this organism as concerned in the etiology of this disease. From our own investigations as well as from those of Hadley and Amison in America, it would seem that the bodies which are so constantly associated with the lesions of the disease in question-the bodies named by Theobald Smith the amœba meleagridis-represent a stage in the life-cycle of this flagellated organism.

\section{Spirochates.}

Near the centre of the accompanying illustration are depicted four spirally-formed organisms, which were encountered in the cæcal and rectal contents of some few of the turkeys examined.

Reference to the figure will show that the spiral organism is unmistakably a spirochæte. It corresponds fairly closely with a similar organism which Fantham recently described as present in the intestinal contents of some of the grouse he examined in Scotland. This organism he named the spirochæte lovati.

The movements of the spirochate now under consideration, when viewed in the fresh state under the microscope, are active, the organism turning, twisting, and vibrating after the manner usual to the spirochætes. The degree of movement, however, exhibited by this organism is decidedly less marked than is that of the blood. inhabiting spirochrete which is met with in fowls at the Cape.

The spirally-formed organism found in the intestinal canal is distinctly thicker than the blood-inhabiting spirochæte last referred to ; moreover, it is shorter and the number of its spiral turns is less, The organism usually appears to taper slightly to each of its extremities. The mode of division, as far as one could make out, appears to be transverse.

A similar spirally-formed organism has also been observed in the rectal and cæcal contents of chickens which appeared to be in quite a healthy condition. It has also been met with in birds the subjects of various diseased conditions, and especially in those in which diarrhoea had been in evidence prior to death.

No evidence is forthcoming that the organism now referred to exerts any harmful effect on its host.

Various other bodies are shown in the accompanying illustration in addition to the trichomonads and spirochretes. Certain of these probably represent stages in the life-cycle of the flagellate, whilst some of the larger bodies are coccidia, and others possibly ova of helminths.

On one or two occasions bodies were encountered in the rectal contents which appeared to be amœbæ in a state of encystment. 